\title{
Elimination of Identity-based Discrimination in Food and Nutrition Programmes in India
}

\author{
Rajendra P. Mamgain and G. Dilip Diwakar*
}

Abstract India's growth story in recent years is being criticised for its inability to reduce the ever-increasing income inequality and higher incidence of malnutrition among its children, particularly those belonging to marginalised groups such as Scheduled Castes (SCs). This article examines the prevalence of identity-based discrimination in health and nutritional programmes and finds it to be one of the important reasons for the higher incidence of malnutrition among SC children. While examining the guidelines of two major nutritional support programmes - the Integrated Child Development Services (ICDS) and the Mid Day Meal (MDM) Scheme - the article argues for making these more caste- and gender-sensitive in order to eliminate discrimination. It offers policy recommendations to address and monitor the discrimination in nutrition programmes. These include greater participation by marginalised groups like SCs in service planning and delivery, ensuring quality and promoting accountability; training and sensitisation of service providers; and the revision of administrative guidelines.

\section{Introduction}

India has made significant progress in economic growth in recent years but its performance in several indicators relating to human development and poverty reduction remains unsatisfactory. There exist significant differences in the levels of such indicators across various social groups in the country. The Scheduled Castes (SCs) and Scheduled Tribes (STs) generally exhibit low levels of development and a high incidence of poverty and malnutrition compared with other social groups (Thorat and Dubey 2012; Sabharwal 2011). The abysmally low nutritional levels among children still remain a major national concern, criticised by scholars, media and civil society organisations.

A recent survey reconfirms the widespread incidence of malnutrition among children under five years of age - about 42 per cent being underweight and nearly 59 per cent stunted (HUNGaMA 2011). The incidence of malnutrition is higher among STs (56.1 per cent) and SCs (50.6 per cent) than 'others' (36.3 per cent) (Thorat and Sabharwal 2011). The Prime Minister of India termed the widespread malnutrition of children as 'National Shame' on releasing the HUNGaMA report.

The determinants of nutritional levels of children have been analysed by several scholars (Sabharwal 2011; Baru et al. 2010; Baraik and Kulkarni 2006; Roy et al. 2004). The incidence of malnutrition is significantly higher among poor households, mothers of children without any education and those belonging to SC and ST social groups. The likelihood of SC children being malnourished is about 1.4 times that of children belonging to other social groups even after controlling for education and health (Sabharwal 2011). One econometric study using longitudinal data from Andhra Pradesh (Himaz 2009) finds being from a scheduled caste or a backward tribe substantially increases the probability of a child being stunted and persistently so. The only other variables to have this effect were lack of mother's education and height, both reflecting discrimination from a generation past.

These results of caste disadvantage in nutritional levels, controlling for socioeconomic determinants, strongly suggest discriminatory

IDS Bulletin Volume 43 Number S1 July 2012 @ 2012 The Authors. IDS Bulletin (c) 2012 Institute of Development Studies Published by Blackwell Publishing Ltd, 9600 Garsington Road, Oxford OX4 2DQ, UK and 350 Main Street, Malden, MA 02148, USA 
access of SC households to health and nutrition programmes both in terms of quantity and quality.

With this background the next section of the article examines the prevalence of identity-based discrimination in the dispensation of the two major nutritional security programmes, the Integrated Child Development Services (ICDS) and the Mid Day Meal (MDM) Scheme. Section 3 examines the guidelines of these programmes and their caste and gender sensitivity in the Indian context. The final section suggests measures for eliminating caste-based discrimination in the delivery of ICDS and the MDM Scheme.

\section{Evidence of identity-based discrimination in food and nutrition programmes}

There is a rich and growing body of literature on various forms of discrimination, its causes and consequences and on policies to promote nondiscriminatory and more inclusive society (Thorat and Newman 2010; de Haan 2001; Kabeer 2000; Sen 2000). In India, exclusion and discrimination revolve around the societal interrelations and institutions that exclude, discriminate against and deprive some groups on the basis of their identity derived from caste, ethnicity, religion and gender (Thorat and Louis 2003). The nature of exclusion revolving around the caste system particularly needs to be understood. Caste may prevent certain social groups from participating fully in the social process while in some contexts it means they can participate but on different terms and conditions from other social groups (Thorat and Lee 2010). This leads to poorer access to income-earning assets, employment, and basic needs like education, health services, housing, and government-provided food security assistance.

A number of evaluation studies undertaken to assess the performance of ICDS and the MDM Scheme in promoting the nutritional status of children and pregnant and lactating women, focus on issues of general accessibility, infrastructure and manpower related to the schemes (Planning Commission 2011, 2010; Pratichi Trust 2010; NIPGCD 2006, 1992; Gupta and Gumber 2001). In particular the recent evaluation studies of ICDS and the MDM Scheme by the Planning Commission bring forth revealing features of the implementation of these two schemes.
In the case of ICDS, the Planning Commission analyses find very low registration of children in the eligible age group in Anganwadi Centres (AWCs) - only 49 per cent. Among the registered children, only 64 per cent received supplementary nutrition - one of the major activities of AWCis. Although an AWC is supposed to provide supplementary nutrition to children for 25 days in a month, the average availability was 16 days in a month. Similarly, around 78.3 per cent of pregnant and lactating mothers were registered in an AWC but they received only 12 days supplementary nutrition per month. The awareness of their entitlements was least among mothers of children and among pregnant women. Services such as supplementary nutrition, health check-ups, referrals and nutrition and health education having direct impact on malnourishment, morbidity and mortality have not been effectively delivered (Planning Commission 2011). The scheme suffers with widespread poor infrastructure facilities coupled with weak monitoring, thus adversely affecting the quality of service delivery. The proximity of an AWG is also an important factor in influencing attendance.

The Mid Day Meal (MDM) Scheme, launched on 15 August 1995 in 2,408 selected blocks in the country, was extended to all blocks in 1997-98. With the intervention of the Supreme Court of India, the scheme was revised in September 2004 to provide a cooked midday meal with 300 calories and $8-12 \mathrm{~g}$ of protein to all children studying in classes I-V in government and government-aided schools and in education guarantee scheme/alternative and innovative education centres. In October 2007, the scheme was further revised to cover children in upper primary classes VI-VIII in 3,479 Educationally Backward Blocks (EBBs).

A recent evaluation study of the MDM Scheme by the Planning Commission (2010) finds no uniform implementation practices for the scheme across different states. For example, in Uttar Pradesh, the Gram Pradhan is responsible for implementation of the scheme through the village education committee and Saraswati Vahini - a group of mothers. Andhra Pradesh implements the scheme on a public-private partnership mode through involving self-help groups and nongovernmental organisations (NGOs). The evaluation study found that most of the states 
were not following the Government of India guidelines to deliver the foodgrain at the school point by Public Distribution System (PDS) dealers and this resulted in leakages in the supply.

The scheme has been successful in eliminating classroom hunger for a majority of sampled beneficiaries; nevertheless, one fifth of students in states like Bihar, Rajasthan and West Bengal report inadequate school meals. There is also a serious shortage of cooks for the MDM Scheme (Planning Commission 2010). The scheme has had a significant impact on improving attendance in schools but not on attracting fresh enrolment in government schools. There has been a spurt in enrolment in private schools over recent years (NUEPA 2012), thus diminishing enrolment in government schools in the country.

The study (Planning Commission 2010) also credits the MDM Scheme for promoting social equity by providing opportunities for children from different social groups to have meals together. In the absence of the scheme, there is evidence of discrimination in serving cooked meals in schools, causing segregation, mental trauma and dropout of children belonging to SCs (Thorat and Lee 2010; Jan Sahas 2009).

The forms of exclusion and discrimination identified by these studies include (1) the location of infrastructure, (2) the nature of the human resources managing the scheme at the grassroots level, and (3) discriminatory practices in providing the service.

\subsection{Location}

The available literature shows how location of the infrastructure facility helps certain groups and hinders access for other groups (Jan Sahas 2009; Thorat and Lee 2005). If the facility is located in another caste habitation it increases the vulnerability of, tensions in and threats to lower castes in attempting to access services in such locations. It also prohibits the access of SC children to such services (Thorat and Lee 2005). If the facility is located in an SC locality, the participation of other castes may decrease due to their self-exclusion as they consider going to an SC locality as inferior. The National Infrastructure Equity Audit (SEW 2011) shows glaring locational disadvantages to SCs in accessing facilities as these are mostly located near upper-caste habitations.

\subsection{Human resource factors}

The success of any welfare scheme largely depends on the people who are engaged in its implementation. Generally, the ICDS and the MDM Scheme have been criticised for irregularities, non-adherence to guidelines and malpractices leading to leakages of benefits to non-beneficiaries and complete denial of service to some target groups (Ramchandran 2004). The evidence shows that dispensation of the MDM Scheme and ICDS is relatively better for SC children if the organisers of these services are also SC (Diwakar 2011; Jan Sahas 2009; Thorat and Lee 2005). However, such generalisations need to be undertaken cautiously. There are equally good examples of better organisation of the service by providers from other castes.

The Planning Commission (2010) shows how the MDM Scheme is constrained due to lack of cooks and helpers. Sometimes this is despite people belonging to SCis being willing to provide their services as cooks and helpers in the MDM Scheme but who are then generally not accepted by other caste groups (Thorat and Lee 2005; Ramchandran 2004). A similar situation exists for the ICDS. Recent field-level observations relating to ICDS reconfirm remarkable caste biases in the delivery of this service (IIDS-UNICEF 2012).

A common complaint relates to not organising Information Education and Communication (IEG) activities to advise and support mothers in SC localities regarding the importance of child nutrition, growth monitoring, personal health and hygiene, dietary requirements, locally available nutritious food, breast feeding, colostrum, complementary feeding, sanitation, etc., thus undermining the objective of ICDS.

\subsection{Discriminatory practices}

Some of the empirical studies have shown active discrimination based on caste identity, such as violating fair norms by directly excluding SC children from the programmes (Mander and Kumaran 2006). Children from upper castes are included in Supplementary Nutrition Programme (SNP) schemes, but marginalised communities are denied access to the services wherever there is more demand from upper castes. Sometimes SC children are included but not treated properly in the AWC. For example, the child is made to feel unwelcome through taunts, selective neglect, is made to sit separately, is 
excluded from extracurricular activities and receives very harsh punishment for misbehaving (IIDS-UNICEF 2012). This kind of treatment disincentivises further SC participation.

Discrimination is not practised at the beneficiary level alone. Service providers from lower castes are discriminated against by the upper castes one example is the refusal to eat in the MDM Scheme and ICDS if the food is prepared by an SC cook (Thorat and Lee 2010; Ramachandran 2004; Menon 2003). Recently a State

Government's effort to promote the participation of SCs as cooks in the MDM Scheme and ICDS, failed miserably with strong opposition from other caste groups. In some cases, there has been a complete refusal of AWCs to provide takehome rations (THR) to pregnant and lactating mothers belonging to SC communities (Jan Sahas 2009).

\section{Policy guidelines for nutrition programmes: How sensitive are these in addressing discrimination in service delivery?}

Government guidelines are aimed at improving the access and quality of the nutrition support services in both the ICDS and the MDM Scheme. They also aim to improve the access of these schemes to the children of SCs and other weaker sections of the society. In the case of ICDS, the guidelines also prohibit the inclusion of political leaders in the selection process of Anganwadi workers (AWW)s. The AWWs are recognised as honorary and grassroots functionaries under the ICDS scheme. These guidelines, however, are silent on ensuring the selection of AWWs from eligible women belonging to SCs and other marginalised groups in proportion to their population.

In order to improve the implementation of the ICDS, the Government has proposed a five-tier monitoring and review mechanism from the central level to the AWC level with a focus on quality improvement. The guidelines are sensitive to monitoring the coverage of SCs/STs and minority concentration habitations with the AWCs, to improving the AWC infrastructure and uniformity of AWC functioning, especially AWCs in SC/ST/minority-concentrated habitations. However, if one looks at the composition of the Anganwadi-level Monitoring and Support Committee of ICDS, no mention is made of the need to ensure fair representation of
$\mathrm{SC} / \mathrm{ST} / \mathrm{Muslim}$ women on the committee (GoI 2011). The monitoring mechanism does not outline the role of various committees, particularly at the Anganwadi level, in dealing with the issues of discrimination in service delivery. These guidelines and monitoring committee roles assume discrimination in ICDS service delivery is non-existent.

It is similar with the MDM Scheme guidelines. The guidelines do not provide any directions to address the issue of discrimination and differential treatment in service delivery. Moreover, in the monitoring committee there is no mention of ensuring larger representation of the marginalised communities in order to bring forth their issues. Thus the guidelines for ICDS and the MDM Scheme are generally silent on making the scheme non-discriminatory and more participatory.

\section{Eliminating identity-based discrimination: Policy recommendations}

To support the provision of non-discriminatory services, community participation in the development and implementation of the programmes needs to be promoted and the use of social accountability mechanisms such as citizen report cards needs to be trialled to improve quality and accountability. This would require measures to build the capacities of civil society organisations promoting the development concerns of SGs and other weaker sections. These measures should initially be delivered by government itself and focus on the quality of provisioning, monitoring and sensitisation, and on revising the implementation guidelines to underpin these aspirations.

\subsection{Service provisioning}

The first set of priorities is to improve the access of the schemes to those who need them most but who have not yet been covered. This would require gearing up the monitoring mechanisms by reviving child protection committees with the participation of Panchayat Raj institutions (PRIs) and self-help groups (SHGs) and representatives from beneficiaries, such as carried out by the MV Foundation in Andhra Pradesh (Sinha 2006). This model could ensure greater participation of SCs and other marginalised communities in the management of the MDM Scheme and ICDS if proper inclusive measures are taken.

Growth monitoring, IEC, house visits, and health referrals should be given importance as these are 
receiving less than the desired attention in service delivery. This may require two workers per AWC, as in Tamil Nadu, up to ICDS phase III - one to provide services to children aged up to three years old such as growth monitoring, house visits, IEC and health referrals, while the other takes care of the children aged three to six years, thus yielding better outcomes for child growth (Heaver 2002).

\subsection{Monitoring}

Regular monitoring is crucial to ensure proper functioning of a programme. There is a need to empower existing committees with clear guidelines relating to the roles and responsibilities of ICDS and MDM Scheme workers. Equally important is giving effective representation to marginalised groups on various committees, particularly at the grassroots level, for better monitoring in their interests. The existing guidelines around monitoring performance need to be made caste-sensitive to address discrimination and exclusion.

Secondly, monitoring by supervisors and the Child Development Project Officer (CDPO) is crucial. As of now people are unaware who to report their problems to regarding malfunctioning of the programme. There is a need to increase CDPO visits to AWCs to at least once in two months and for them to focus on interacting with the communities at AWCs. At present the CDPOs mainly check the stock and look at other administrative work (Diwakar 2011). The gearing up of monitoring activities, ensuring prompt actions against defaulting actors and rewarding good work, would go a long way in building confidence among poor and weaker sections in demanding their entitlements.

\subsection{Training and sensitisation}

There is a need for periodic training in service delivery and management for line department workers involved in ICDS and the MDM Scheme - it is very weak at present (IIDS-UNICEF 2012). Students and teachers from schools of social work, home science colleges, medical colleges and other voluntary agencies need to be engaged on a large scale in training functionaries at the grassroots level. This would also require the production and distribution of training materials among service providers. The IEG material should focus on sensitising all service providers, including higher officials, on methods of promoting non-exclusionary and nondiscriminatory nutritional support services to target groups. Sensitising training should also be provided to grassroots-level workers as well as local opinion leaders. Community-level awareness of the impact of exclusion and discrimination needs to be increased. The government should resist pressure from upper castes to bar SCis and other marginalised groups from being employed as cooks in the MDM Scheme and ICDS.

The intermingling of children from different castes is very important for future social cohesion. Preschool education in the ICDS is one such opportunity to bring children together through play. Unfortunately, in many of the centres, the preschool is non-existent, frequently due to lack of education materials. These materials need to be provided to all centres.

\subsection{Administrative guidelines}

Outside of the MDM Scheme and ICDS, there is a legal framework for addressing discrimination based on caste and religion. But within the programmes there are few administrative guidelines to safeguard the interests of marginalised and poor communities. The scheme-specific guidelines need to be revised to deter discriminatory practices in service delivery. Rather than taking harsh punitive action against those who violate those guidelines, which are generally weak in implementation in any case, the best-performing ICDS and MDM Scheme should be rewarded for their work in rendering a high-quality service at the cluster, block, district, state and national level - for all citizens. Administrative guidelines should be modified in line with identified best practice within ICDS and the MDM Scheme. The guidelines should ensure active participation of PRIs, mothers, pregnant women, community leaders of SGs and other civil society organisations in quality service delivery.

\section{Conclusions}

This article reminds the reader of the evidence confirming the persistently higher level of undernutrition faced by children from SGs. It reviews the evidence on how the ICDS and MDM Scheme favour children and mothers who are not from SCs. It reviews the programme guidelines for delivering these government schemes and finds them lacking in sensitivity to the weak status of SC groups in decision-making and 
quality monitoring and finds the guidelines silent on how to address the discrimination that is uncovered. Aware of the deep-rooted discrimination in Indian society and the challenges that arise in overcoming them, this article makes a number of recommendations on what the ICDS and MDM Scheme can do differently: greater participation by marginalised groups like SC communities in service planning

\section{Notes}

* The authors are Director and Associate Fellow, respectively, of the Indian Institute of Dalit Studies, New Delhi. We thank Biraj Swain and Lawrence Haddad for providing the

\section{References}

Baraik, Vijay Kumar and Kulkarni, P.M. (2006) Health Status and Access to Health Care Services Disparities among Social Groups in India, IIDS Working Paper 1.4, New Delhi: Indian Institute of Dalit Studies

Baru, Rama; Acharya, A.; Acharya, S.; Kumar, S.A.L. and Nagaraj, K. (2010) 'Inequalities in Access to Health Services in India: Caste, Class and Region', Economic and Political Weekly 45.38: 49-58

de Haan, Arjan (2001) Social Exclusion: Enriching the Understanding of Deprivation, Working Paper, prepared for the World Development Report, Brighton: Poverty Research Unit, University of Sussex

Diwakar, G. Dilip (2011) 'Integrated Child Development Service in Kancheepuram District, Tamil Nadu: Issues of Access to Marginalised Communities', unpublished thesis, submitted to Center of Social Medicine and Community Health, Jawaharlal Nehru University, New Delhi

GoI (Government of India) (2011) Guidelines for Constitution of Monitoring and Evaluation Committees, Ministry of Women and Child Development, F.No.16-8/2010ME, www.wcd.nic.in (accessed 5 March 2012)

Gupta, Devendra B. and Gumber, Anil (2001) Concurrent Evaluation of Integrated Child Development Services: National Report, New Delhi: National Council of Applied Economic Research (NCAER)

Heaver, Richard (2002) India's Tamil Nadu Nutrition Programme: Lessons and Issues in Management and Capacity Development, HNP Discussion Paper, Washington DC: World Bank and its delivery, ensuring quality and promoting accountability more generally; training and sensitisation of service providers; and the revision of administrative guidelines to detect, address and monitor discrimination. These programmes cannot be expected to short-circuit deep-seated discrimination, but neither should they reinforce it.

opportunity to write this article. We are grateful to Sukhadeo Thorat, Nidhi Sadana Sabharwal and K.K. Singh for their valuable comments. The usual disclaimers also apply.

Himaz, R. (2009) 'Persistent Stunting in Middle Childhood: The Case of Andhra Pradesh Using Longitudinal Data', IDS Bulletin 40.4: 30-8

HUNGaMA (2011) Fighting Poverty and Nutrition, Hunger and Malnutrition Report, New Delhi: Nandi Foundation

IIDS-UNICEF (2012) Social Inclusion in Multiple Spheres (ongoing), New Delhi: Indian Institute of Dalit Studies

Jan, Sahas (2009) 'Exclusion and Inclusion of Dalit Community in Education and Health: A Study', mimeo, Dewas, Madhya Pradesh: Jan Sahas Social Development Society

Kabeer, Naila (2000) 'Social Exclusion, Poverty and Discrimination: Towards an Analytical Framework', IDS Bulletin 31.4

Mander, Harsh and Kumaran, M. (2006) 'Social Exclusion in ICDS: A Sociological Whodunit?', mimeo, New Delhi: Centre for Equity Studies

Menon, Parvathi (2003) 'Untouchable Lunch', Frontline 20.15

NIPCGD (2006) Three Decades of ICDS: An Appraisal, New Delhi: National Institute of Public Cooperation and Child Development

NIPCCD (1992) Evaluation of Integrated Child Development Services, New Delhi: National Institute of Public Cooperation and Child Development

NUEPA (2012) State Report Cards, 2010-11: Elementary Education in India - Where Do We Stand? (provisional), New Delhi: National University of Educational Planning and Administration

Planning Commission (2011) Evaluation Report on Integrated Child Development Service, Programme Evaluation Organisation, New Delhi: Government of India 
Planning Commission (2010) Performance

Evaluation of Cooked Mid-Day Meals, Programme Evaluation Organisation, Report 202, New Delhi: Government of India

Pratichi Trust (2010) The Mid-Day Meals Programme in Urban Primary and Rural Upper Primary Schools in West Bengal, Pratichi (Trust) India, Kolkatta: S.S. Print

Ramachandran, Vimala (2004) Analysis of Positive Deviance in ICDS Programme - Rajasthan and Uttar Pradesh, New Delhi: World Bank

Roy, T.K.; Sumati, K. and Vaidehi, Y. (2004) 'Social Inequalities in Health and Nutrition in Selected States', Economic and Political Weekly 39:7: 677-83

Sabharwal, S. Nidhi (2011) 'Caste, Religion and Malnutrition Linkages', Economic and Political Weekly 46.50: 16-18

Sen, A.K. (2000) Social Exclusion: Concept, Application and Scrutiny, Social Development Paper 1, Philippines: Asian Development Bank SEW (2011) National Equity Infrastructure AuditPhase 1, Briefing Paper 2, New Delhi: Social Equity Watch

Sinha, Dipa (2006) 'Rethinking ICDS: A RightsBased Perspective', Economic and Political Weekly 41:34: 3689-84
Thorat, Sukhadeo and Dubey, Amaresh (2012) 'Has Growth Been Socially Inclusive?', Economic and Political Weekly 47.10: 43-54

Thorat, Sukhadeo and Lee, Joel (2010) 'Food Security Schemes and Caste Discrimination', in S.K. Thorat and K.S. Newman (eds), Blocked by Caste: Economic Discrimination in Modern India, USA: Oxford University Press: 287-310

Thorat, Sukhadeo and Lee, Joel (2005), 'Caste Discrimination and Food Security Programmes', Economic and Political Weekly 39:24: 4198-201

Thorat, Sukhadeo and Louis, Prakash (2003) Exclusion and Poverty in India: Scheduled Castes, Tribes and Muslims (overview paper), New Delhi: Department for International Development Thorat, S.K. and Newman, K.S. (eds) (2010) Blocked by Caste: Economic Discrimination in Modern India, USA: Oxford University Press

Thorat, S.K. and Sabharwal, N.S. (2011) 'Addressing the Unequal Burden of Malnutrition', India Health Beat, www.phfi.org/ images/pdf/Policy_Note_Vol5_5.pdf (accessed 15 November 2011) 